\title{
Editorial: New directions in lifelong learning
}

\section{A special feature for the London Review of Education}

\author{
Lorena Sanchez Tyson* and Valerie Watson Vega - UCL Institute of \\ Education, UK
}

The 2030 UN Sustainable Development Goals places quality education and lifelong learning (LLL) opportunities for all at the forefront of the international agenda for global transformation (UN General Assembly, 2015). In this context, LLL perspectives have become increasingly important in contemporary education studies.

A key example of the influence of the international LLL agenda was the establishment of the Erasmus Mundus Master's in Lifelong Learning: Policy and Management (MA LLL) in 2006. Through a consortium between the Danish School of Education (DPU), Aarhus University, the Institute of Education (IoE), University of London (now a faculty of University College London), Universidad de Deusto (UD), Bilbao, and the Melbourne Graduate School of Education (MGSE), University of Melbourne, the MA LLL became the first programme of its kind aimed at enhancing global education perspectives and addressing the rapid transformation of LLL policies and practices across a wide range of organizational contexts (Blakemore and Lloyd, 2010).

From 2015 to 2017, we formed part of the final cohort of MA LLL students travelling and studying in multiple countries. Inspired by our transnational experiences, we wanted to draw attention to the widely different professional trajectories and research that former MA LLL graduates are involved in and provide evidence of how joint schemes like this can be a platform to emerging scholars around the world.

For this special feature, we invited contributions from established and emerging researchers with links to the MA LLL to submit articles reflecting the highest quality research carried out during their studies or upon completion of the programme. Lifelong learning encompasses many themes and areas of research and, as such, the articles in this special feature represent a sample of the wide range of debates, issues and innovative practices in lifelong learning in the contexts of India, Ethiopia and two Latin American countries. Furthermore, we believe that the diverse themes addressed in this feature are a testament to the international dimension of the MA LLL programme.

The cooperation and collaboration between higher education institutions and researchers across borders is more important today than ever before, encouraging mutual recognition and trust and facilitating the international mobility of students and professionals. This collaboration holds the potential to bridge international understandings and shape new directions of scholarship in all disciplines. We hope that the content of this special issue for the London Review of Education helps to drive the debate on LLL forward and, ultimately, encourages further scholarship in the field.

We want to thank the contributors who remained dedicated to this special issue from its conception in 2017 and whose work represents the scope and breadth of LLL as a field of study. In particular, we would like to thank Professor Paul Morris for his mentorship and guidance throughout the process, as well as Dr Itziar Elexpuru, 
Dr Marcella Milana and Dr Samantha Duncan for their support. We also acknowledge the invaluable feedback from the peer reviewers. Finally, we want to recognize the ongoing work of the global MA LLL community that we are proud to be a part of.

\section{Notes on the editors}

Lorena Sanchez Tyson is a doctoral candidate in the Department of Education, Practice and Society at UCL Institute of Education. She holds a BA in English from the Universidad Autónoma de Tamaulipas (Mexico), and an MA in Lifelong Learning: Policy and Management. Her research focuses on adult literacy in multilingual and multicultural contexts; other interests include literacy, lifelong learning, unschooling, alternative learning, and indigenous and intercultural education.

Valerie Watson Vega is an MA in Lifelong Learning: Policy and Management at UCL Institute of Education (UK) and the Universidad de Deusto (Spain). She has a BA in Educational Psychology from Pontificia Universidad Católica del Perú, where she was a Psychology Faculty member. She has extensive experience in higher education contexts and the development of training programmes in Latin America and the UK. Her research interests focus on the development of higher education and social justice.

\section{Articles in this London Review of Education feature}

Mandal, S. (2019) 'The rise of lifelong learning and fall of adult education in India: Towards a new beginning or end of an era?' London Review of Education, 17(3), 318-30.

Molla, T. (2019) 'Educational Aid, Symbolic Power and Policy Reform: The World Bank in Ethiopia'. London Review of Education, 17(3), 331-46.

Sanchez Tyson, L. and Watson Vega, V. (2019) 'Why we need to talk about lifelong learning and intercultural universities'. London Review of Education, 17(3), 347-61.

\section{References}

Blakemore, M. and Lloyd, P. (2010) Erasmus Mundus Quality Assessment Project: Quality handbook. Brussels: European Commission.

United Nations (UN) General Assembly. (2015) Transforming Our World: The 2030 Agenda for Sustainable Development. Online. https://tinyurl.com/y2s8wt4e (accessed 24 October 2019). 